\title{
Development of centrifugal slurry pumps in tailings disposal and comparison with positive displacement pumps
}

\author{
J Crawford FLSmidth KREBS, USA \\ N Bessett FLSmidth KREBS, USA
}

\begin{abstract}
This paper covers FLSmidth KREBS ${ }^{\circledR}$ pump development, over the past 10 years, of an extensive range of high-pressure centrifugal slurry pumps for multistage applications. The primary objective has been to produce safe, economical, energy efficient and maintenance friendly centrifugal slurry pumps to fulfil the expanding requirements of the mineral processing industries in the long distance transportation of tailings and mineral slurries. Two ranges of pumps have been developed, a double cased pump (based on the KREBS rubber lined slurryMAX ${ }^{T M}$ XD pump) and an unlined white iron cased pump (based on the millMAX ${ }^{T M}$ pump).

The logic behind the development of the two pump ranges will be explained in depth covering the design and first article production, getting it right. The methodology of the hydraulic and structural criteria requirements that are considered during the pumps' design are integrated with the use of computational fluid dynamics and finite element analysis to ensure that the pumps perform safely, reliably and with maximum efficiency.

Application of the pumps to projected operating data is explained taking into consideration specific needs for flange and foundation loads, maintenance and condition monitoring. Consideration of slurry rheology and its implication on pumping performance is discussed.

Cost comparison between actual field data and the theoretical positive displacement (PD) costs, as presented at the 21st International Seminar on Paste and Thickened Tailings, will be analysed in the Appendix.
\end{abstract}

Keywords: energy efficient, safety, rheology, cost comparison

\section{Introduction and history of KREBS millMAX pumps}

John Frater, an inductee to the International Mining Hall of Fame, the inventor of the millMAX pump, started off his career in Manchester, England, when he joined a water pump company called Mather \& Platt. In the early 1960s, Frater became the production manager of the then licensee of Warman in England. In 1980, he started the Orion Pump Company and designed the Orion pump. In 1984, the Orion Pump Company was sold to Joy Manufacturing, which at the time owned Denver Equipment.

In 1994, Frater moved to Australia and designed a new pump with an innovative suction side sealing concept. Solving the hydraulic recirculation problem has been a key focus for pump designers since the advent of wet processing of mineral ores. The first millMAX pump was installed in Western Australia in 1995 and immediately proved itself to be a successful pump design, so other sizes soon followed. KREBS bought the rights to the millMAX design in August 1999. KREBS became part of FLSmidth in 2007 and has now built over 17,000 pumps with various ranges covering all major applications within the mineral processing industry.

\subsection{Product range}

In all KREBS ${ }^{\circledast}$ horizontal slurry pumps, the key feature is the externally adjustable wear ring that minimises slurry recirculation from the high-pressure zone in the casing back to the low-pressure zone at the impeller eye. This enables a greater clearance between the front impeller shroud and liner, reducing shear and further improving overall wear rates as well as reducing the efficiency correction factors required, resulting in lower power consumption in operation. Being externally adjustable, the pumps do not have to be shut down or 
disturbed when performing the simple adjustment. The KREBS horizontal slurry pump range covers rubber lined and uncased metal units (Figure 1) from 50 to $850 \mathrm{~mm}$ suction with power frames to 3,700 kW and designs to cover practically all mineral processing applications. The KREBS pump ranges best suited to high-pressure (HP) and extra high-pressure (XHP) tailings applications include the millMAX HP, ultimate mill discharge (UMD) HP and the slurryMAX XHP. Advances specific to tailings applications include development of rubber suction sideliners for metal cased pumps and the option of rubber or laser clad tungsten carbide wear rings.
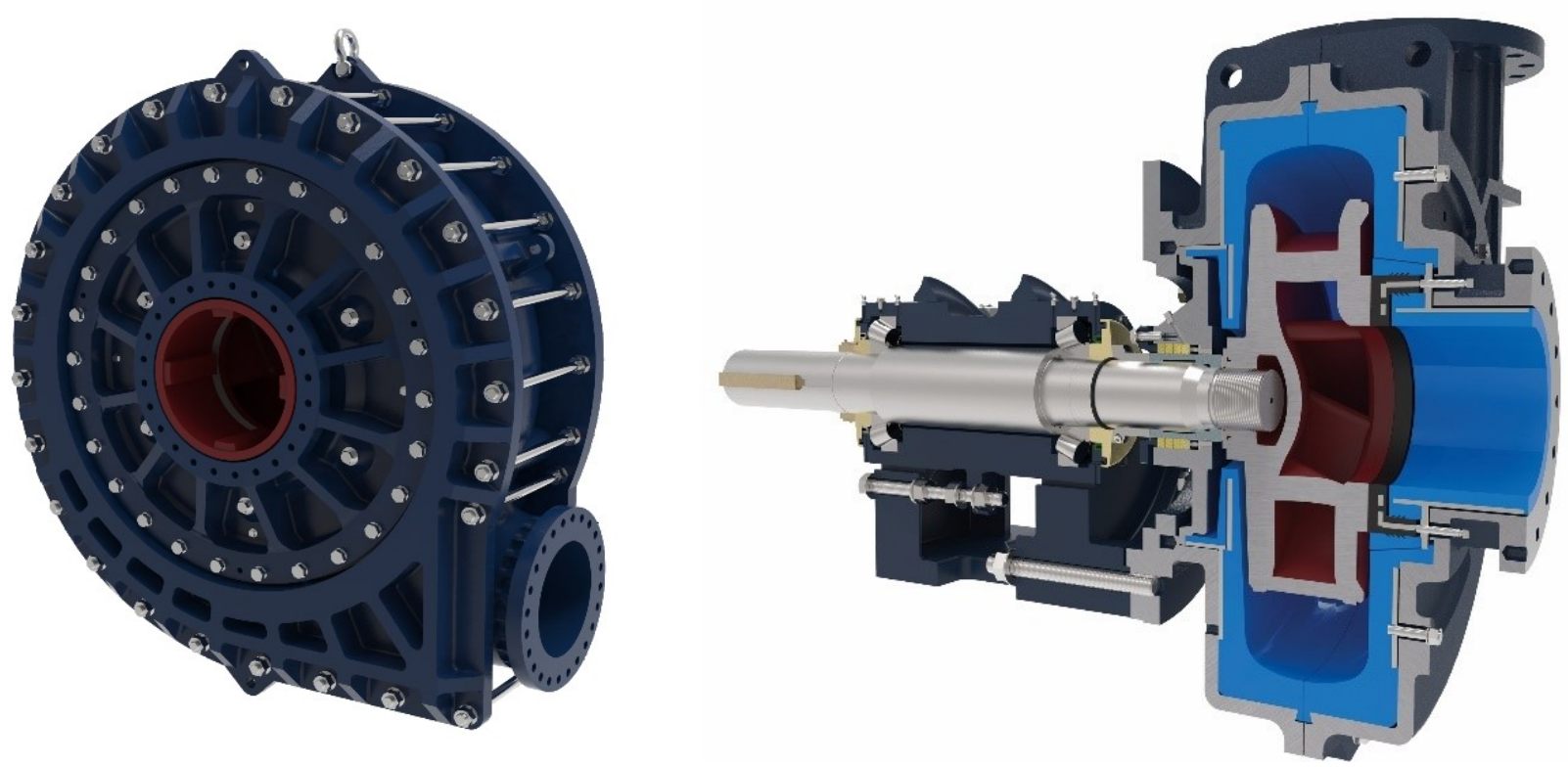

Figure 1 Images of rubber lined and uncased metal pumps

\section{$1.2 \quad$ KREBS pump models}

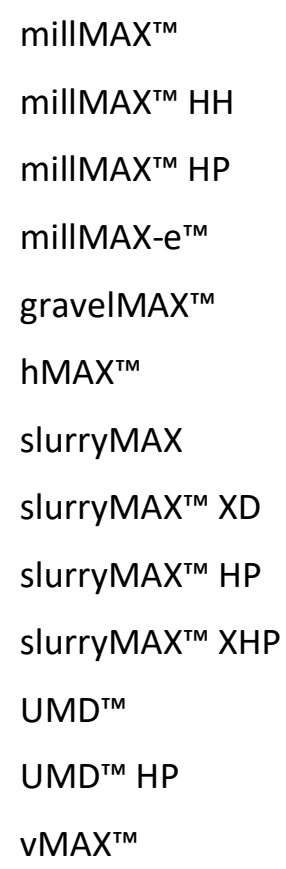

Horizontal metal cased slurry pump.

High head horizontal metal cased slurry pump.

High-pressure horizontal metal cased slurry pump.

High efficiency horizontal metal cased slurry pump.

Metal cased pump with large solids handling.

Horizontal carbon transfer pump

Double walled pump with wide range of impeller and liner materials.

Rubber lined slurry pump.

High-pressure rubber lined slurry pump.

Extra high-pressure rubber lined slurry pump.

Extreme duty mill circuit pump.

High-pressure extreme duty mill circuit pump.

Vertical sump pump. 


\section{$2 \quad$ High-pressure pumps: uncased metal}

Market demand from Amec and Teck for the new Andacollo copper mine in Chile was the driver for development of the high-pressure version millMAX unlined metal casing pump. These were first installed in the tailings disposal system, where 10 pumps in total are installed in two trains of five pumps, with each pump generating up to $690 \mathrm{kPa}$ pressure.

The challenge of a $3.45 \mathrm{MPa}$ operating pressure with a 5.17 MPa hydrostatic test pressure was addressed using a fundamental design concept of containing the high-pressure using cast steel plates and high tensile bolts as opposed to cast iron outer casings. Operational experience after more than five years shows average wet end life between rebuilds in excess of 12,000 hours.

The use of the unlined design concept has additional advantages. It enables the casing thickness to be measured and monitored while the pump is running, assisting maintenance planning. As shown in Figure 2, the casing bolts form an effective containment ring around the casing to ensure safety in operation where catastrophic events such as water hammer might occur.

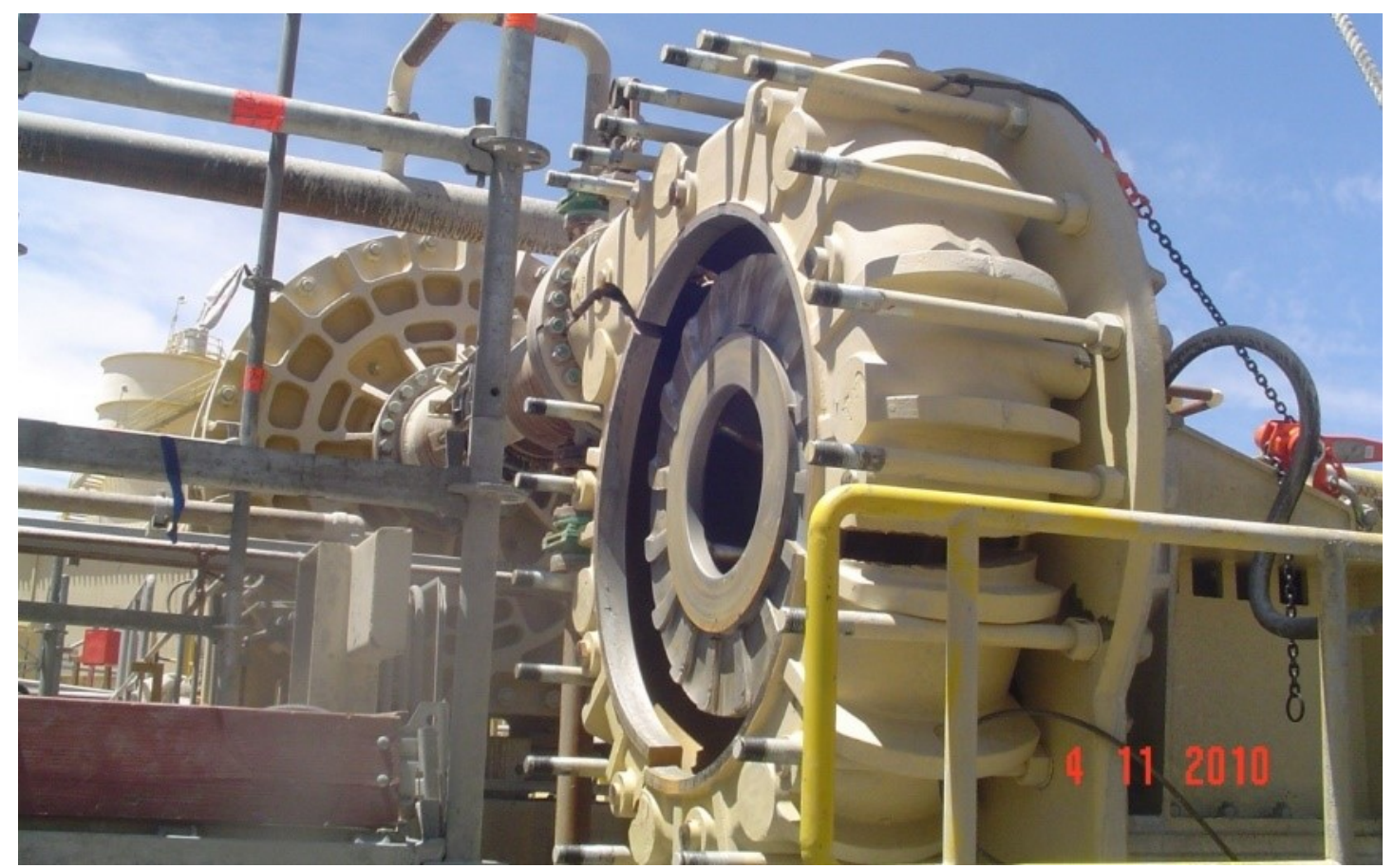

Figure $220 \times 18$ millMAX HP after water hammer event. Note failed sections safely contained by casing bolts

Particular consideration was given to the gland service water (GSW) system design, installation and control to ensure adequate gland seal reliability. Each tailings pump unit was provided with its own dedicated GSW pump, thus ensuring close control of flush water flow and pressure. For multistage tailings systems, this approach proves more reliable than manifold or ring main fed systems, as each pump operates at significantly different pressures.

\subsection{Ultimate mill discharge (UMD) high-pressure}

Development of the UMD version of the high-pressure pump followed discussions and negotiations with Syncrude, the primary oil sands operator in Alberta, Canada. The requirement was for a $28 \times 26$ size pump with a maximum working pressure of $3.74 \mathrm{MPa}$ and hydrostatic test pressure of $5.52 \mathrm{MPa}$. Due to the large maximum particle size, the UMD pump range originally designed for extreme abrasive applications, having a large impeller aspect ratio and very thick wear components was developed for the required pressure. The final bare shaft pump weighed over 55 tonnes, the heaviest pump FLSmidth has ever built (Figure 3). The trial has been successfully completed showing reduced cost, improved efficiency and extended wear life. 


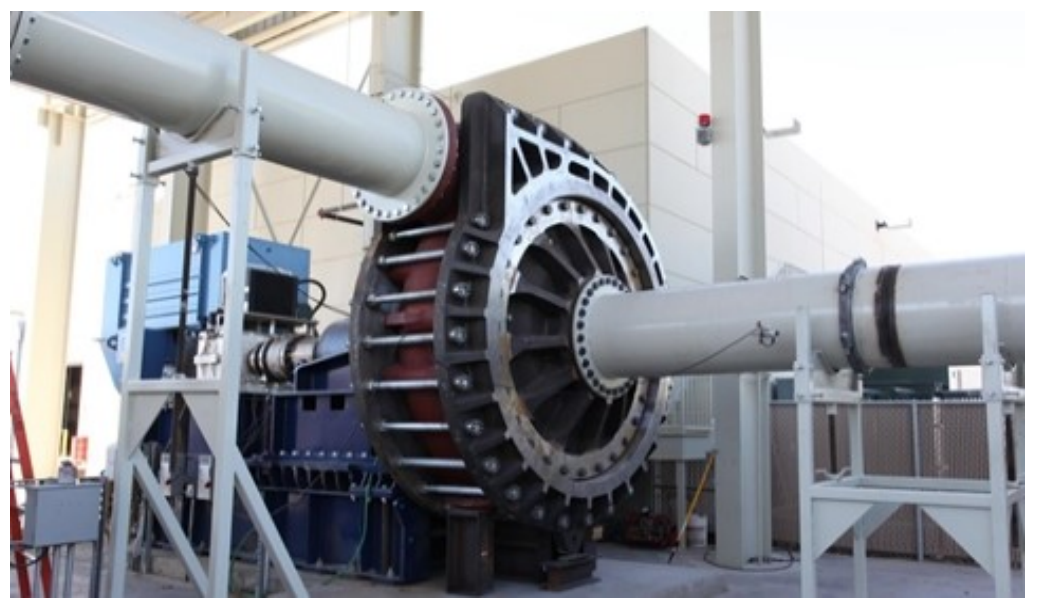

Figure $328 \times 26$ UMD HP in FLSmidth performance testing circuit

\section{$3 \quad$ High-pressure pumps - rubber lined}

\subsection{Development driver}

Operating experience has shown that for very fine slurries, metal and rubber pumps show similar abrasion resistance. However, the selection of the right pump for particular slurries with varying particle size distribution (PSD) can be complex. Slurries with coarser PSD, typically with a d50 from 120 to, say, 500 microns, rubber liners can significantly outlast metal components, provided there is no oversize material, which would exceed the elastomer's resilience and cause damage. This drove demand for a range of high-pressure rubber lined pumps for multistage tailings applications having a coarser PSD. FLSmidth developed high-pressure double cased pumps based on the slurryMAX XD design using rubber liners interchangeable with the standard range (Figure 4). Pumps are rated for $3.45 \mathrm{MPa}$ maximum operating pressure, achieved by strengthening the outer casing.

A significant limitation of rubber-lined pumps in tailings applications is the maximum impeller tip speed before hysteresis is induced. Above a certain threshold, pulses of pressure from the expelling vanes running in close proximity to liners imparts energy leading to localised thermal failure. To achieve higher speed, slurryMAX XD pumps can be configured with 'bald' impellers whereby the front and rear shroud is cast smooth (without expelling vanes). This increases allowable tip speed and thus head per stage without causing hysteresis damage, also increasing the published efficiencies by a few percentage points.

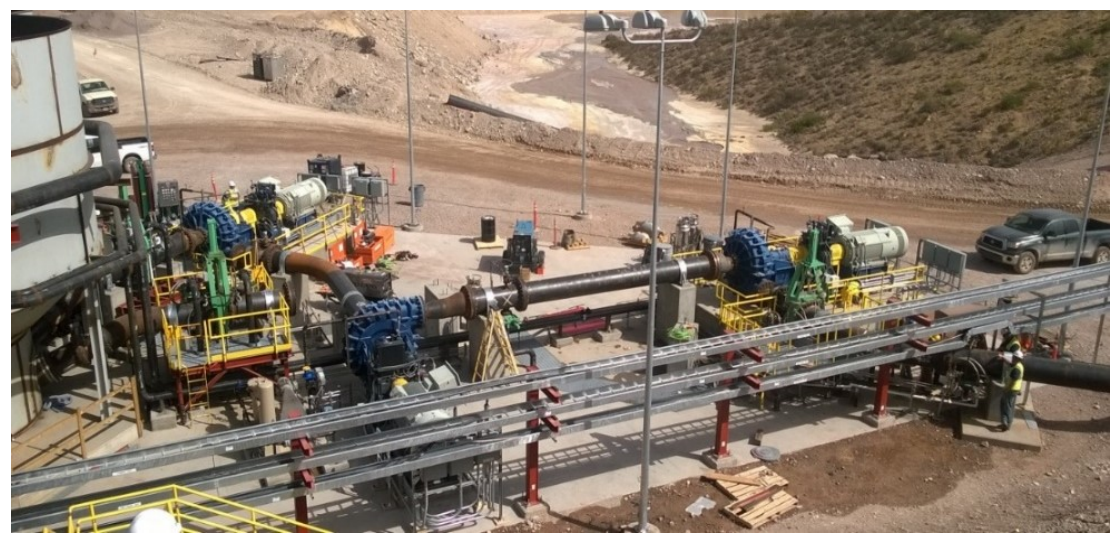

Figure 4 Freeport Morenci tailings system showing three in series $16 \times 14$ slurryMAX HP rubber lined pumps

Recent developments include rubber impeller wear rings for streams with PSDs suited to use of rubber liners. This has shown longer life with less cost and highlighted that where condition of the wear ring can be maintained, life of the surrounding components can also be extended. 


\section{$4 \quad$ Pump and foundation loads}

\subsection{Sources of pump and foundation load}

External forces acting on a pump include mechanical loads, displacement loads and hydraulic loads.

Mechanical loads result from the mass of the pumpset and pipework, the contents of which are applied directly onto the pump nozzles and pipe supports. These can be a significant source of loading in poorly engineered installations. Special pipe couplings or other components used to accommodate pipework may influence other loads in the system.

Displacement loads are due mainly to movement of the pipework from changes in pressure or temperature. Thermal loads result from the expansion and contraction of the pipework between two fixed points (including the pump as a fixed point). Generally, thermal displacement loads will be greatest when the pump and pipework is empty as contained fluid limits the expansion coefficient.

Hydraulic loads result from pressure and momentum forces acting on the pump and pipework. Momentum loads are unbalanced but are usually much smaller than pressure loads.

In mineral processing applications, pipework is often significantly oversized to reduce velocity and minimise wear. Relatively high pressures involved in multistage tailings pumping acting on significant diameter differences in pipework can produce large hydraulic loads. Additionally, for some piping arrangements, typically straight inter-stage pipe work, flexibility is required to remove pipework without moving the pumpset. Unless axially restrained, flexible pipe couplings and maintenance joints pass hydraulic load onto the pump nozzles and must be designed accordingly. Please refer to Table 1 for a full comparison of inter-stage piping arrangements.

\section{Table 1 Comparison of inter-stage piping arrangements}

\begin{tabular}{|c|c|c|}
\hline Arrangement & Advantages & Disadvantages \\
\hline \multirow{4}{*}{$\begin{array}{l}\text { Parallel shaft } \\
\text { arrangement } \\
\text { (inter-stage } \\
\text { bends) }\end{array}$} & Simple pump station layout & $\begin{array}{l}\text { Large diameter systems require } \\
\text { significant space }\end{array}$ \\
\hline & Easy to install and remove piping & Wear on bends \\
\hline & Common pump plinth elevation & \multirow{2}{*}{$\begin{array}{l}\text { For large pipe diameters, bends must } \\
\text { be supported }\end{array}$} \\
\hline & Separation of wet and dry areas & \\
\hline \multirow{5}{*}{$\begin{array}{l}\text { Right angle } \\
\text { shaft with } \\
\text { flexible } \\
\text { couplings }\end{array}$} & Simple piping layout & \multirow{2}{*}{$\begin{array}{l}\text { Hydraulic pressure loads act on pump } \\
\text { base }\end{array}$} \\
\hline & Low nozzle loads & \\
\hline & Easy to remove piping & \multirow{3}{*}{$\begin{array}{l}\text { Pump plinth elevations vary to } \\
\text { accommodate the height difference } \\
\text { between the pump suction and } \\
\text { discharge }\end{array}$} \\
\hline & Pump misalignment absorbed by joints & \\
\hline & Shorter footprint for larger diameter piping & \\
\hline \multirow{3}{*}{$\begin{array}{l}\text { Right angle } \\
\text { shaft with } \\
\text { rigid joints }\end{array}$} & $\begin{array}{l}\text { Simple piping layout } \\
\text { Shorter footprint for larger diameter piping }\end{array}$ & $\begin{array}{l}\text { High nozzle loads with thermal and } \\
\text { hydraulic load effects }\end{array}$ \\
\hline & Large hydraulic pressure loads & $\begin{array}{l}\text { Pump plinth elevations vary to } \\
\text { accommodate the height difference } \\
\text { between pump suction and discharge }\end{array}$ \\
\hline & & Specials required to install piping \\
\hline
\end{tabular}




\subsection{Magnitude and direction}

The magnitude and direction of the loads depends on the pumpset and pipework layout. Some combinations of layout, discharge position and pipe work arrangement can increase loads and moments acting in certain directions to the point of using the pump as an anchor. For example, it should be noted that hydraulic thrust load applied to the discharge nozzle, being tangential to the casing's centre, results in a bending moment applied about the base and foundation. In very high-pressure applications, the loads are significant so the addition of stabilising feet on the hub plate may be necessary. This requires prior consideration in the foundation design, which may be wider than normal to accommodate the wider footprint.

\subsection{Limitations}

Pumps are examples of rotating equipment requiring precise alignment; therefore, minimising piping loads via good system design is desirable from the mechanical and maintenance points of view. Aside from coping with loads from a material strength perspective to avoid failure, it should be remembered that displacement leads to misalignment, which can adversely affect reliability. Consider water flushed glands or mechanical seals, where a relatively small misalignment can lead to product leakage and premature seal failure.

Where loads will exceed the manufacturer's recommended loads, piping should be anchored in close proximity to the pump or pipework connected in such a way that prevents transmission of excessive loads to the pump nozzles.

FLSmidth initiated a major investigation to identify typical forces and flange loads for single and multistage pump installations as well as performing finite element analysis (FEA) to establish practical maximum nozzle load limits to ensure safe and reliable operation with acceptable margins. We have determined from this work that by applying the limits proposed in ANSI/Hydraulic Institute Standard 12.1-12.6 (Hydraulic Institute 2016) we ensure that millMAX pumps will not be adversely affected by nozzle loads considering appropriately designed single or multistage installations.

\subsection{Solutions for coping with excessive nozzle loads}

A number of solutions to cope with excessive nozzle loads exist and are described in the following sections.

\subsubsection{Axially restrained pipe couplings}

Flexible pipe couplings (as shown in Figure 5) at the suction and discharge nozzle are frequently found in low-pressure (single stage) applications. Caution must be taken when using them in multistage applications where high pressures act on differences in suction and discharge diameters. Large nozzle loads result, increasing the mechanical requirements on the pump, foundations and anchor bolts. The use of axially restrained flexible couplings such as those with tie rods, described in ANSI/Hydraulic Institute Standard 9.6 Appendix D (Hydraulics Institute 2009), results in effective self-balanced systems, minimising the loads on the pump while allowing some misalignment and all the convenience of flexible couplings during installation and maintenance. 


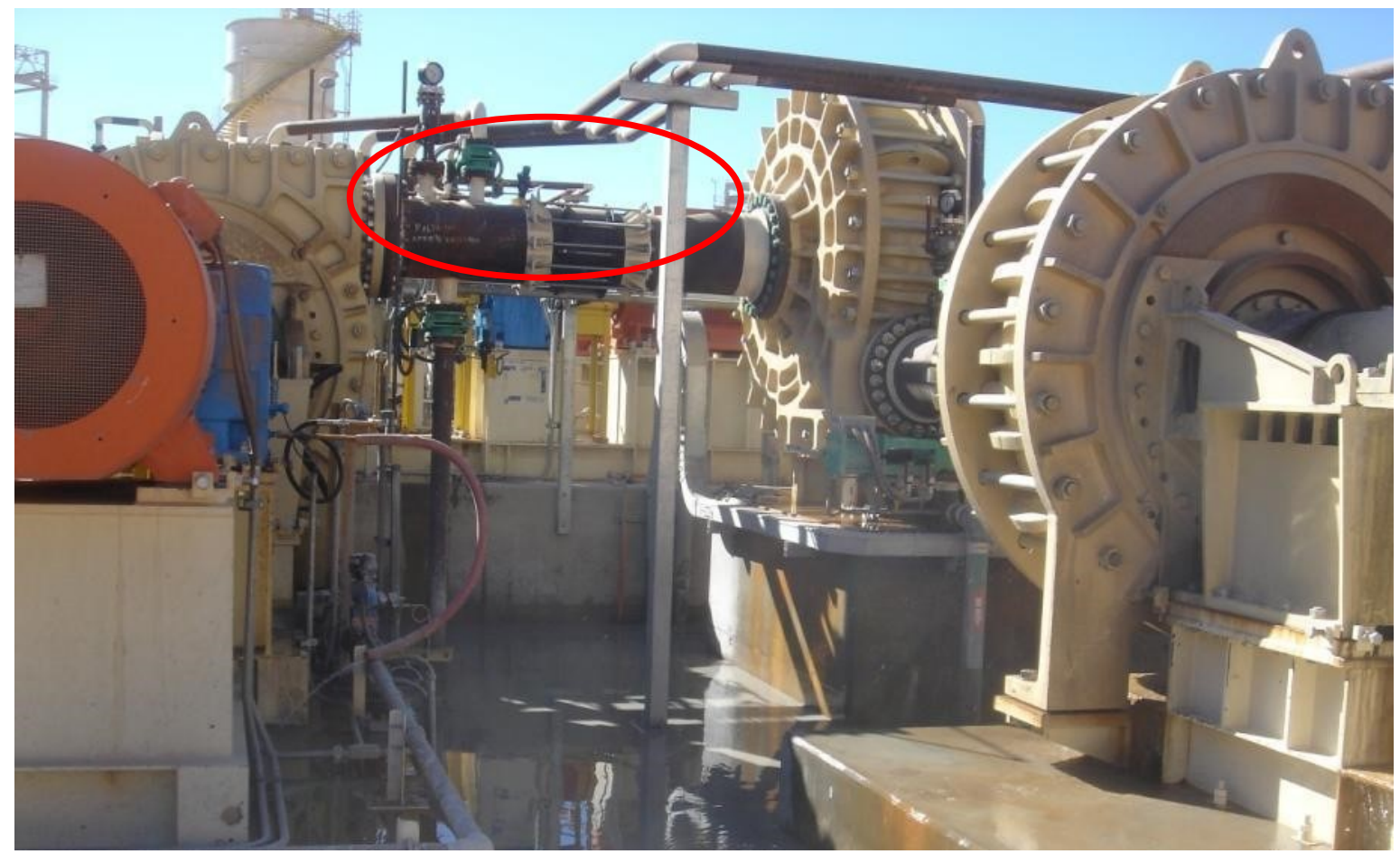

Figure 5 Inter-stage pipework showing a reducer and axially restrained coupling

\subsubsection{Pipe anchors}

Where loads cannot be restrained or thermal expansion compromises the degree to which axially restrained pipe couplings relieve the pump nozzles, pipework anchors can be used. These must withstand any displacement of the pipe and prevent transmission of load to the pump. These are most often found on the discharge of the final pump stage; however, where there are many stages (more than three or four) there may also be a requirement for pipework anchors between stages.

\subsubsection{Pipework bends}

A simple way of avoiding hydraulic loads being passed on to the pump nozzles is to use a $90^{\circ}$ bend between each pump stage and on the discharge of the final stage where maximum nozzle loads would otherwise be exceeded. This approach can accommodate large radius bends and gentle transition in diameters to minimise wear and inter-stage friction losses. Designed correctly, the cost of using bends to reduce nozzle loads is minimal compared with using pipework anchors, heavier pump casings and foundations, and axially restrained couplings, etc. (Figure 6). 


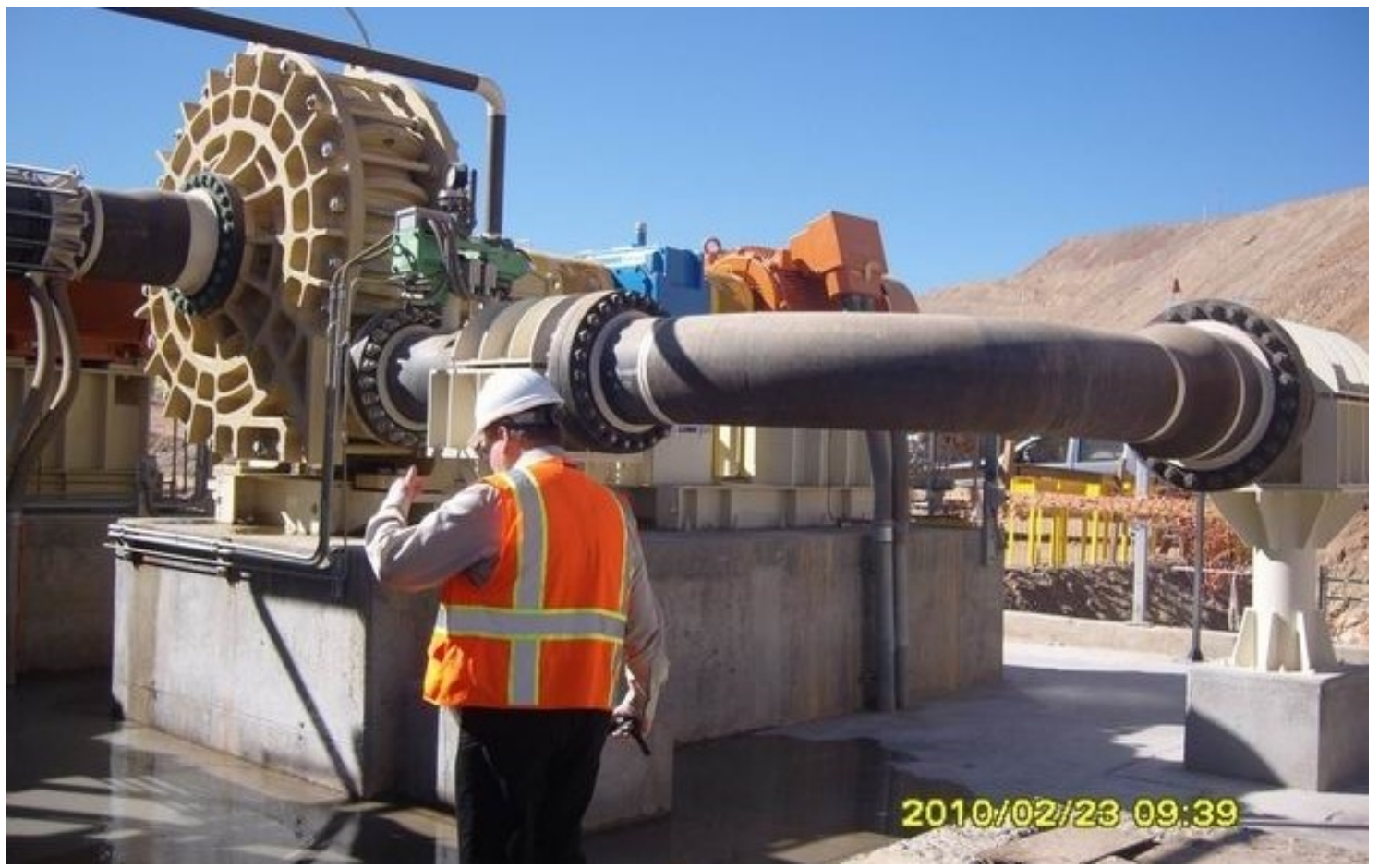

Figure 6 Teck Andacollo tailings system showing fifth stage discharge with use of pipe supports/anchors and bends to contain hydraulic loads

\subsubsection{Pump design}

Although it has been done and remains an option, changing standard pump designs to accommodate specific nozzle loads is possible but should be avoided due to the significant development costs and loss of standardisation stemming from using custom-made pump components. It is generally preferable for the end user to have standard equipment rather than address the plant engineering issues.

\section{$5 \quad$ Slurry rheology}

Slurry rheology, and its effect on pump performance, needs to be considered when selecting and operating multistage tails systems. Thickened tailings and paste are produced in deep cone and similar thickeners to produce slurries with minimum water content. A side effect of these high-density slurries is the generation of high Bingham yield stress. The consequence of the yield stress is to significantly affect the pump performance, so it is necessary to consider the consequential de-rating of the pump due to changed head and efficiency ratios.

The yield stress generated by thickening is broken down partially by energy imparted into the fluid during the pumping operation. It is essential to ensure that sufficient power is available to fulfil this task.

FLSmidth commissioned some ultra-viscous pumping test work with the objective to establish centrifugal slurry pump performance over a range of extreme viscosity and yield stress slurries. As shown in Figure 7, a $6 \times$ 4-16 millMAX pump was run in a test loop and solids concentration varied to produce various viscosity and yield stress values (fully sheared). A paper based on this test work was presented at the 15th International Seminar on Paste and Thickened Tailings (Crawford et al. 2012). 

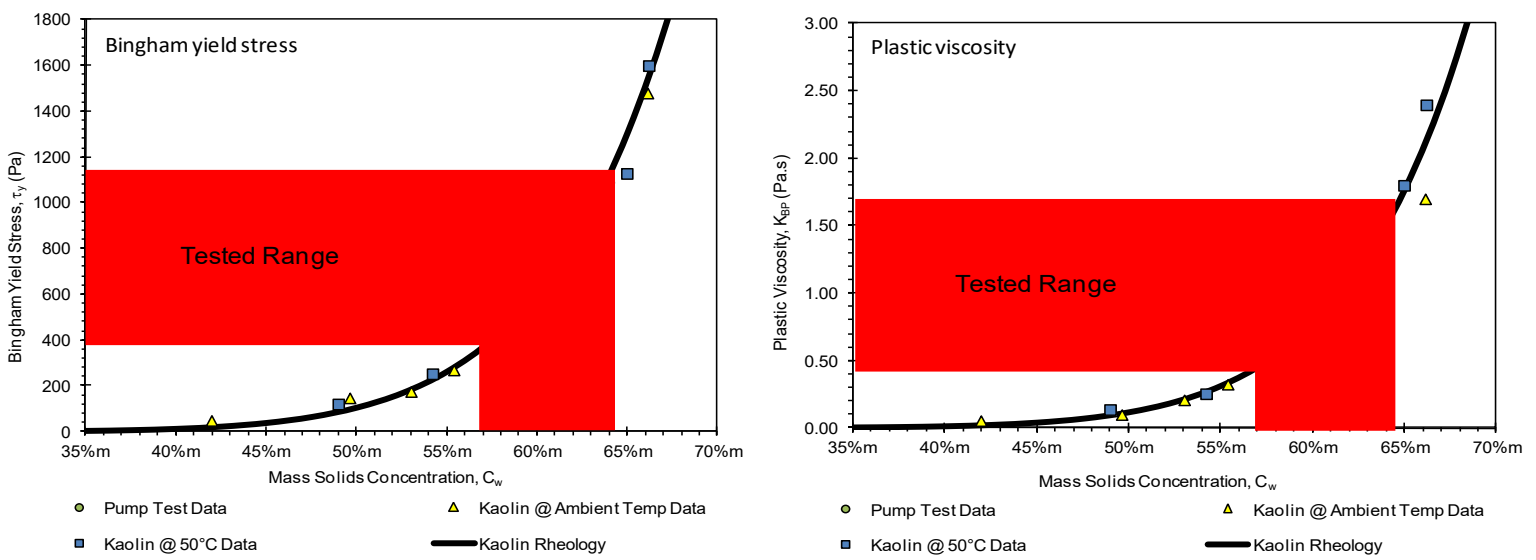

Figure 7 Test range of Bingham yield stress and mass solids concentration pumped by a millMAX pump

Figures 8 and 9 show the head and efficiency ratios measured during the testing demonstrating the significance of the corrections required, particularly on efficiency.

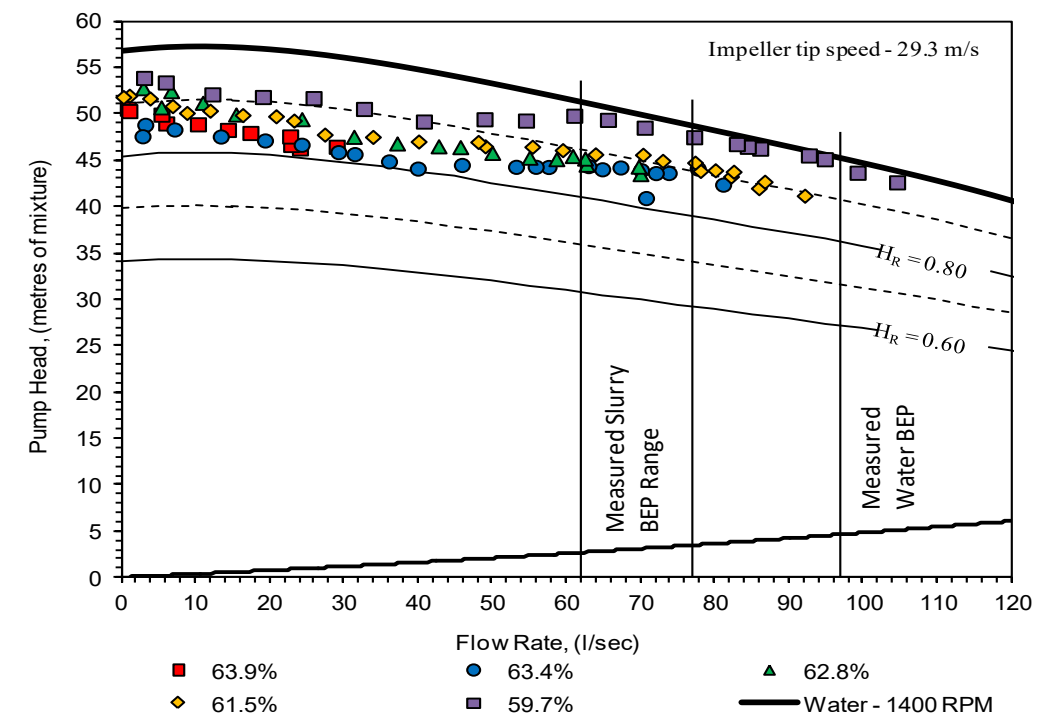

Figure 8 Showing head and flow for a range of solids concentrations and the resulting $\mathrm{Hr}$ values

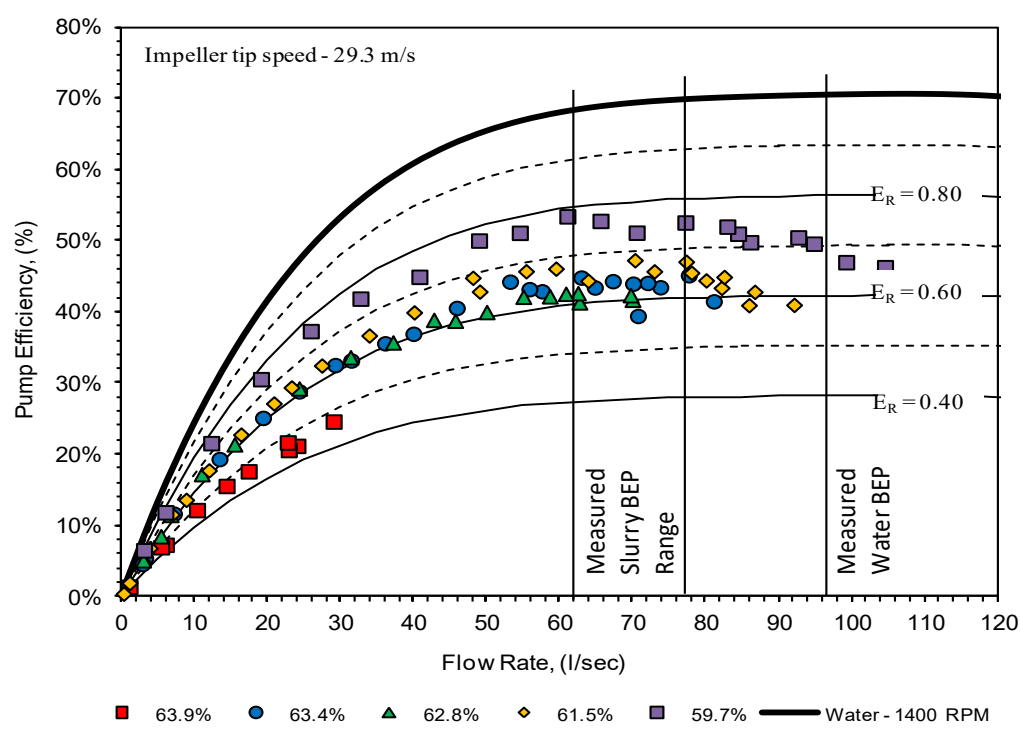

Figure 9 Showing head and flow for a range of solids concentrations and the resulting Er values 
Illustrating the extreme range of yield stress is an image of the Boger slump test taken at the highest value of yield stress, 1,120 kPa, which was still successfully pumped (Figure 10).

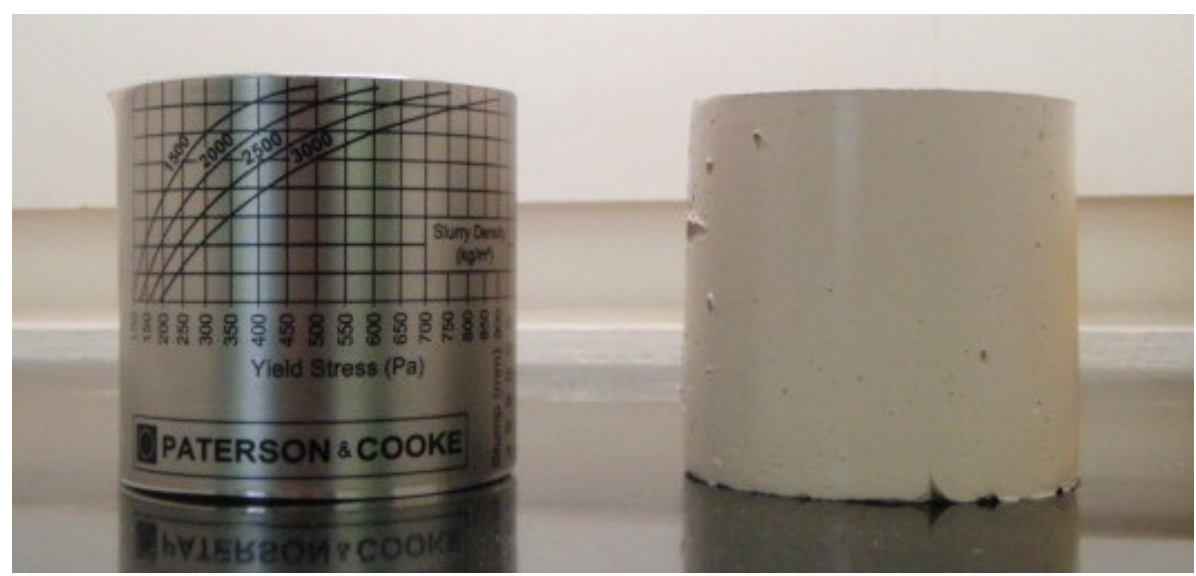

Figure 10 Slurry with 1,120 Pa yield stress successfully pumped with a 6 × 4-16 millMAX

One of the main conclusions drawn from this rheology test work was that slurries with much higher yield stress and plastic viscosities than previously thought can be pumped successfully.

\section{Conclusion}

Centrifugal slurry pumps are ideally suited for long distance tailings disposal. Special attention is required in the pump design and construction as well as installation design to ensure that all projected flange loads are adequately catered for. Good gland sealing is essential for system reliability.

The Appendix provides a cost comparison between actual field data for centrifugal pumps and the theoretical positive displacement costs as presented at the 21st International Seminar on Paste and Thickened Tailings by Krimpenfort (2018).

\section{Appendix}

\section{A1 Comparison of data from paper presented at the 21st International Seminar on Paste and Thickened Tailings by Krimpenfort (2018): Technical review of used data for centrifugal pumps}

\section{A1.1 Efficiency of centrifugal slurry pumps}

The efficiencies of centrifugal slurry pumps have evolved from the range nominated in the paper and are now above the $50-70 \%$ range quoted. The KREBS pump used in this analysis (UMD $20 \times 18 \mathrm{HP}$ ) maintains its efficiency throughout the life cycle as the pump includes an anti-suction side recirculation devise.

The efficiency of this pump is $81 \%$ for the nominated duty.

\section{A1.2 Pressure rating of centrifugal slurry pumps}

Generally, it has not been necessary to exceed 35 bar for tailings systems. We have developed pumps with higher ratings as required specifically for oil sands and Australian iron ore operations. A 50 bar has now become readily acceptable (note: FLSmidth is currently bidding pumps rated at over 75 bar).

\section{A1.3 Gland seal water}

Yes, centrifugal slurry pumps operating at high-pressure require GSW. As stated in the early part of this paper, it is vitally important to address this issue in the design stage of the project. The well-designed and dedicated 
GSW system used at Teck Andacollo Mine in Chile has proven the logic of such a system during the nine years of trouble-free operation.

\section{A1.4 Third lines and positive displacement pump in system}

None of the major multi-stage tailings pipeline systems using centrifugal pumps the writer has encountered over the past 30 years had a third line or a PD pump included. This includes the seven and eight stage systems at La Disputada in Chile, and Kelian in Indonesia.

\section{A1.5 Response to capital expenditure comparison}

The centrifugal pump selected for this duty is the KREBS UMD $20 \times 18 \mathrm{HP}$. This is the latest version of our HP tailings pumps that can be either metal or rubber lined. By using these pumps, it is only required to have a total of 16 pumps $2 \times(4+4)$. Each pump will generate 6.25 bar to achieve the required 50 bar final discharge pressure.

Most of the basic data as used in Krimpenfort (2018) has been used in the calculations, viz cost of pumps, capital expenditure (CAPEX) for pumps station installations (per pump), engineering, procurement and construction management (EPCM) and contingency \% and power costs. Please refer to modified Table 2. Note that there is no need for a 'deblocking piston pump'. All costs are in euros for comparison purposes.

Table 2 Capital expenditure comparison

\begin{tabular}{|c|c|c|c|}
\hline & $\begin{array}{l}\text { Centrifugal pump } \\
2 \times(4+4) \\
5,000 \mathrm{~m}^{3} / \mathrm{hr}\end{array}$ & $\begin{array}{l}\text { MCPD } \\
7+1 \\
713 \mathrm{~m}^{3} / \mathrm{hr}\end{array}$ & $\begin{array}{l}\text { HCPD } \\
5+1 \\
1,000 \mathrm{~m}^{3} / \mathrm{hr}\end{array}$ \\
\hline No. of required pump units & 16 & 8 & 6 \\
\hline $\begin{array}{l}\text { Price per pump (average including } \\
\text { gearbox, motor, VFD) (EUR) }\end{array}$ & 450,000 & $2,300,000$ & $2,800,000$ \\
\hline No. of operating pumps & 8 & 7 & 5 \\
\hline No. of standby pumps & 8 & 1 & 1 \\
\hline No. of charge pumps for PD pumps & - & 4 & 3 \\
\hline No. of standby charge pumps & - & 2 & 2 \\
\hline Price per charge pump (EUR) & - & 80,000 & 120,000 \\
\hline \multicolumn{4}{|l|}{ Calculation } \\
\hline Total system pump CAPEX (EUR) & $7,200,000$ & $18,880,000$ & $17,400,000$ \\
\hline $\begin{array}{l}\text { CAPEX of balance of plant and pump } \\
\text { station (BOP) }\end{array}$ & $15,360,000$ & $22,656,000$ & $17,400,000$ \\
\hline Total direct cost (EUR) & $22,560,000$ & $41,536,000$ & $34,800,000$ \\
\hline EPCM (12\%) (EUR) & $2,707,200$ & $4,984,320$ & $4,176,000$ \\
\hline Contingency (15\%) (EUR) & $3,384,000$ & $6,230,400$ & $5,220,000$ \\
\hline Total CAPEX pump station(s) (EUR) & $28,651,200$ & $52,750,720$ & $44,196,000$ \\
\hline Difference in investment (EUR) & - & $-24,099,520$ & $-15,544,800$ \\
\hline
\end{tabular}

No consideration has been given to the increased capital cost of the piping system that will be required when operating PD pumps. 
The Krimpenfort (2018) calculations for power consumption overestimated the power required for centrifugal pumps. The efficiency of the KREBS pumps that are operating on similar duties is $81 \%$. Consequently, for comparison purposes, the power consumption has been recalculated (Table 3).

Table 3 Power consumption comparison

\begin{tabular}{|c|c|c|c|}
\hline & $\begin{array}{l}\text { Centrifugal pump } \\
2 \times(4+4) \\
5,000 \mathrm{~m}^{3} / \mathrm{hr}\end{array}$ & $\begin{array}{l}\text { MCPD } \\
7+1 \\
713 \mathrm{~m}^{3} / \mathrm{hr}\end{array}$ & $\begin{array}{l}\text { HCPD } \\
5+1 \\
1,000 \mathrm{~m}^{3} / \mathrm{hr}\end{array}$ \\
\hline Pressure (bar) & 50 & 50 & 50 \\
\hline Capacity $\left(\mathrm{m}^{3} / \mathrm{hr}\right)$ & 5,000 & 5,000 & 5,000 \\
\hline Price per kWhr (EUR) & 0.12 & 0.12 & 0.12 \\
\hline Operating hours (per year) & 8,500 & 8,500 & 8,500 \\
\hline Assumed efficiency (\%) & 81 & 88 & 88 \\
\hline \multicolumn{4}{|l|}{ Calculation } \\
\hline Absorbed power (kW) & 8,573 & 7,891 & 7,891 \\
\hline Hourly power cost (EUR) & 1.22 & 946 & 946 \\
\hline Annual power cost (EUR) & $8,744,856$ & $8,049,242$ & $8,049,242$ \\
\hline $\begin{array}{l}\text { Difference in power consumption } \\
\text { per year (EUR) }\end{array}$ & - & 695,614 & 695,614 \\
\hline
\end{tabular}

Although a relatively small component of total operating costs, the amount used in the Krimpenfort (2018) comparison seems to be based on primary cyclone feed/mill discharge pumps (Table 4). Experience at the Teck Andacollo Mine in Chile shows wear parts costs are averaging less than USD 400,000 for the 10 pumps installed. For this exercise, an annual figure of USD 700,000 (effectively 600 EUR) has been estimated.

Table 4 Wear part cost comparison

\begin{tabular}{|c|c|c|c|}
\hline & $\begin{array}{l}\text { Centrifugal pump } \\
2 \times(4+4) \\
5,000 \mathrm{~m}^{3} / \mathrm{hr}\end{array}$ & $\begin{array}{l}\text { MCPD } \\
7+1 \\
713 \mathrm{~m}^{3} / \mathrm{hr}\end{array}$ & $\begin{array}{l}\text { HCPD } \\
5+1 \\
1,000 \mathrm{~m}^{3} / \mathrm{hr}\end{array}$ \\
\hline \multicolumn{4}{|l|}{ Field experience } \\
\hline Annual pump wear part cost (EUR) & 600 & 483,000 & 420,000 \\
\hline $\begin{array}{l}\text { Difference in wear parts cost per } \\
\text { year (EUR) }\end{array}$ & - & 117,000 & 180,0000 \\
\hline
\end{tabular}

Field experience at Andacollo is that there are about 40 man-hours per pump per annum spent on maintenance. For the sake of this exercise, we will use 100 hours. Consequently, the annual cost is 48,000 (EUR) (Tables 5 to 7). 
Table 5 Labour cost comparison

\begin{tabular}{|c|c|c|c|}
\hline & $\begin{array}{l}\text { Centrifugal pump } \\
2 \times(4+4) \\
5,000 \mathrm{~m}^{3} / \mathrm{hr}\end{array}$ & $\begin{array}{l}\text { MCPD } \\
7+1 \\
713 \mathrm{~m}^{3} / \mathrm{hr}\end{array}$ & $\begin{array}{l}\text { HCPD } \\
5+1 \\
1,000 \mathrm{~m}^{3} / \mathrm{hr}\end{array}$ \\
\hline No. of required pumps & 16 & 8 & 8 \\
\hline $\begin{array}{l}\text { Maintenance man-hours per year per } \\
\text { pump (hrs) }\end{array}$ & 100 & 200 & 250 \\
\hline Labour cost per hour (EUR) & 30 & 30 & 30 \\
\hline \multicolumn{4}{|l|}{ Calculation } \\
\hline Annual labour maintenance costs (hrs) & 48,000 & 48,000 & 45,000 \\
\hline Difference in labour costs per year (EUR) & - & 0 & 3,000 \\
\hline
\end{tabular}

Table 6 Gland seal water cost comparison (use unchanged)

\begin{tabular}{|c|c|c|c|}
\hline & $\begin{array}{l}\text { Centrifugal pump } \\
2 \times(4+4) \\
5,000 \mathrm{~m}^{3} / \mathrm{hr}\end{array}$ & $\begin{array}{l}\text { MCPD } \\
7+1 \\
713 \mathrm{~m}^{3} / \mathrm{hr}\end{array}$ & $\begin{array}{l}\text { HCPD } \\
5+1 \\
1,000 \mathrm{~m}^{3} / \mathrm{hr}\end{array}$ \\
\hline Power cost gland water pumps (EUR) & 11,475 & 4,590 & 3,442 \\
\hline GSW consumption (at $1.5 \mathrm{~m}^{3} / \mathrm{hr}$ per pump) $\left(\mathrm{m}^{3} / \mathrm{y}\right)$ & 127,500 & 51,000 & 38,250 \\
\hline GSW cost (at EUR $0.40 / \mathrm{m}^{3}$ ) (EUR) & 51,000 & 20,400 & 15,300 \\
\hline \multicolumn{4}{|l|}{ Calculation } \\
\hline Annual costs GSW system (EUR) & 62,475 & 24,990 & 18,742 \\
\hline Difference GSW costs per year (EUR) & - & 37,485 & 43,732 \\
\hline
\end{tabular}

Table 7 Comparison summary

\begin{tabular}{|c|c|c|c|}
\hline & $\begin{array}{l}\text { Centrifugal pump } \\
2 \times(4+4) \\
5,000 \mathrm{~m}^{3} / \mathrm{hr}\end{array}$ & $\begin{array}{l}\text { MCPD } \\
7+1 \\
713 \mathrm{~m}^{3} / \mathrm{hr}\end{array}$ & $\begin{array}{l}\text { HCPD } \\
5+1 \\
1,000 \mathrm{~m}^{3} / \mathrm{hr}\end{array}$ \\
\hline Annual power consumption (EUR) & $8,744,856$ & $8,049,242$ & $8,049,242$ \\
\hline Annual pump wear parts costs (EUR) & 600 & 483,000 & 420,000 \\
\hline Annual labour costs (EUR) & 48,000 & 48,000 & 45,000 \\
\hline Annual gland water costs (EUR) & 62,475 & 24,990 & 18,742 \\
\hline $\begin{array}{l}\text { Annual operating expenditure (OPEX) } \\
\text { (sub-total) (EUR) }\end{array}$ & $8,855,931$ & $8,605,232$ & $8,532,984$ \\
\hline Contingency (15\%) (EUR) & $1,328,390$ & $1,290,784$ & $1,279,947$ \\
\hline Total annual OPEX (EUR) & $10,184,321$ & $9,896,017$ & $9,812,932$ \\
\hline Difference in OPEX per month (EUR) & & 24,025 & 30,949 \\
\hline Total CAPEX (EUR) & $28,651,200$ & $52,750,720$ & $44,196,000$ \\
\hline $\begin{array}{l}\text { Amortisation period of difference in } \\
\text { investment (years) }\end{array}$ & - & 99 years & 77 years \\
\hline
\end{tabular}




\section{A2 Conclusion}

The primary issues in comparing the total capital and operating costs from the assumptions in Krimpenfort (2018) regarding centrifugal pumps and the Feluwa pumps are summarised.

\section{A2.1 Capital costs}

Krimenpenfort (2018) deemed it necessary to use 20 pumps in two lines and two pump stations. In the comparison, only 16 pumps are required in two lines and again two pump stations. Hence, for the centrifugal pumps, the capital costs have been reduced by $20 \%$.

\section{A2.2 Comparison of power cost}

Krimpenfort (2018) had used pump efficiency of $68 \%$. The pump used in the centrifugal pump application at the duty point is $81 \%$. This has reduced the annual cost of power by about 1.8 million euros.

\section{A2.3 Comparison of parts and labour}

Data from the Andacollo operation (two lines of five pumps) have been used in the calculations with a $12 \%$ addition to allow for the increased duty.

\section{A2.4 Gland seal costs}

Not changed from Krimpenfort (2018): In conclusion, the experience at Andacollo and other sites where KREBS pumps are installed demonstrate the reliability of centrifugal pumps in high flow and pressure tailings applications.

\section{Acknowledgement}

The authors acknowledge FLSmidth KREBS, USA; Paterson \& Cooke Cape Town laboratory personnel; Teck Carmen de Andacollo copper mine, Chile; Freeport McMoran Morenci Mine; and Syncrude Canada Ltd for support in their text.

The authors acknowledge that some parts of this paper appeared in a paper published in the Proceedings of the 3rd International Seminar on Tailings Management in 2015 (Newman et al. 2015).

\section{References}

Crawford, J, van Sittert, F \& van der Walt, M 2012, 'The performance of centrifugal pumps when pumping ultra-viscous paste slurries', in R Jewell, AB Fourie \& A Paterson (eds), Proceedings of the 15th International Seminar on Paste and Thickened Tailings, Australian Centre for Geomechanics, Perth, pp. 297-308.

Hydraulics Institute 2009, Rotodynamic Pumps for Pump Piping (ANSI/HI 9.6.6), Hydraulic Institute, Parsippany.

Hydraulic Institute 2016, Rotodynamic (Centrifugal) Slurry Pumps (ANSI/HI 12.1-12.6), Hydraulic Institute, Parsippany.

Krimpenfort, H 2018, 'A comparison between various pump systems for high flow rate tailings pipelines', in RJ Jewell \& AB Fourie (eds), Proceedings of the 21st International Seminar on Paste and Thickened Tailings, Australian Centre for Geomechanics, Perth, pp. 155-168.

Newman, C, Crawford, J \& Bernhardt, R 2015, 'Development and experience with multi-stage high pressure pumping using centrifugal slurry pumps', in S Barrera (ed.), Proceedings of the 3rd International Seminar on Tailings Management, Gecamin Ltda., Santiago. 